\title{
Intercalation of Aceclofenac/Sulfobutyl Ether- $\beta$-cyclodextrin Complex into Layered Double Hydroxides through Swelling/Restoration Reaction and Its Controlled-Release Properties
}

\author{
Shifeng Li, ${ }^{1}$ Tan Zhang, ${ }^{1}$ Min Xiao, ${ }^{2}$ Zhigang Zhang, ${ }^{1}$ Wenxiu Li, ${ }^{1}$ and Jing Bai ${ }^{3}$ \\ ${ }^{1}$ Liaoning Provincial Key Laboratory of Chemical Separation Technology, Shenyang University of Chemical Technology, \\ Shenyang 110142, China \\ ${ }^{2}$ College of Environment, Shenyang University, Shenyang 110044, China \\ ${ }^{3}$ School of Chemical Engineering and Energy, Zhengzhou University, Zhengzhou 450001, China
}

Correspondence should be addressed to Shifeng Li; li.shi.feng@163.com and Jing Bai; baijing@zzu.edu.cn

Received 4 August 2014; Accepted 21 October 2014; Published 12 November 2014

Academic Editor: Antonios Kelarakis

Copyright (C) 2014 Shifeng Li et al. This is an open access article distributed under the Creative Commons Attribution License, which permits unrestricted use, distribution, and reproduction in any medium, provided the original work is properly cited.

\begin{abstract}
Aceclofenac (AC)/sulfobutyl ether- $\beta$-cyclodextrin (SBE- $\beta$-CD) inclusion complex intercalated layered double hydroxides (LDHs) composite were prepared by swelling/restoration method. After swelling/restoration, the $d$-spacing of LDHs is expanded to $2.23 \mathrm{~nm}$, which clearly demonstrates the successful intercalation of AC/SBE- $\beta$-CD into LDHs layer. AC/SBE- $\beta$-CD inclusion complex in the interlayer has monolayer arrangement based on the $d$-spacing of LDHs and torus thickness of SBE- $\beta$-CD. The AC release performances were also studied in buffer solutions with different $\mathrm{pH}$ values. The results show AC/SBE- $\beta$-CD intercalated LDHs not only enhance the dissolution profile of $\mathrm{AC}$ but also exhibit a controlled-release process, which indicates that the $\mathrm{AC} / \mathrm{SBE}-\beta$ $\mathrm{CD}-\mathrm{LDH}$ have a potential application in drug delivery agent.
\end{abstract}

\section{Introduction}

The organic/inorganic nanocomposites are promising hybrid materials, which exhibit many unique properties due to the synergies of the inorganic and organic components [1]. Layered double hydroxides (LDHs) are a large class of anionic clays consisting of positively charged brucitelike layers and exchangeable interlayer anions $[2,3]$. By intercalation, organic molecules/LDHs composite materials have been widely studied due to the characteristic of tunable composition and exchangeable anion in fields of catalysis, adsorption, controlled-release of drug molecules, UV/IR absorption materials, and so forth [4-10]. Macrocyclic compounds, one important group of organic compounds in host-guest chemistry with excellent applications on structural assembly and molecule/ion recognition, on the other hand, can act as guest components for the composites [11]. In the recent decade, macrocyclic compounds such as cyclodextrins [12-16], calixarenes [1, 17-19], and crown ethers $[11,20]$ intercalated into LDHs have attracted intensive attention because of their potential novel properties. For the preparation of these composites, most traditional methods are coprecipitation, ion-exchange, calcination/rehydration, and delamination/restoration which usually needed long time or heating/refluxing treatment [1]. Recently, a new swelling/restoration method reported by Ma's group $[1,19,20]$ showed similar advantage as delamination for facile entrance of bulk guests, while it can give better morphology. However, to the best of our knowledge, there is no report on the synthesis and applications of cyclodextrins (CDs) or their derivatives intercalated LDHs composite materials through swelling/restoration reaction.

Aceclofenac (AC) is a nonsteroidal anti-inflammatory drug (NSAID) which has shown marked therapeutic effects in rheumatoid arthritis, osteoarthritis, and ankylosing spondylitis $[21,22]$. However, the side effects of gastrointestinal irritation and sparingly aqueous solubility limit practical use of AC [23]. Therefore, it seems a good option for 
intercalation of $\mathrm{AC} /(\mathrm{CDs})$ inclusion complex into $\mathrm{LDHs}$ to reduce side effects and provide an effective therapy for arthritis with lose dose and duration of therapy.

In this work, a swelling/restoration approach for intercalation of AC/sulfobutyl ether- $\beta$-cyclodextrin (SBE- $\beta$-CD) complex into LDHs was proposed. The structure and controlled-release property of $\mathrm{AC} / \mathrm{SBE}-\beta-\mathrm{CD}$ intercalated LDH composite were investigated.

\section{Materials and Methods}

2.1. Materials. $\mathrm{Mg}\left(\mathrm{NO}_{3}\right)_{2} \cdot 6 \mathrm{H}_{2} \mathrm{O}, \mathrm{Al}\left(\mathrm{NO}_{3}\right)_{3} \cdot 9 \mathrm{H}_{2} \mathrm{O}, \mathrm{NaOH}$, $\mathrm{NaNO}_{3}$, and formamide were purchased from Sinopharm Chemical Reagent Co., Ltd. (China). Aceclofenac (AC) was obtained from Wuhan Xinjialing Biotechnology CO., Ltd. (China). SBE- $\beta$-CD (average degree of sulfobutyl ether substitution of 6.5) was purchased from Shandong Binzhou Zhiyuan Biological Technology Co., Ltd. (China). All reagents were used as raw materials without further purification. $\mathrm{CO}_{2}$-free deionized water was used throughout the experimental processes.

2.2. Synthesis of Inclusion Complex of AC with SBE- $\beta-C D$. The inclusion complex of AC with SBE- $\beta$-CD with $1: 2$ molar ratios was prepared using similar kneading method [24]. Accurately weighed quantities of SBE- $\beta$-CD and $\mathrm{AC}$ were taken in a mortar; a minimum volume of ethanol/water ( $1: 1$, by volume) mixture was added slowly and kneaded thoroughly with a pestle to obtain a paste. To remove the $\mathrm{AC}$ adsorbed on the surface of SBE- $\beta-\mathrm{CD}$, the inclusion complex was washed with ethanol solution for several times. The obtained solid mass was further dried under vacuum at room temperature.

2.3. Synthesis of $\mathrm{MgAl}-\mathrm{NO}_{3}-\mathrm{LDHs}$. The $\mathrm{MgAl}-\mathrm{NO}_{3}-\mathrm{LDHs}$ was prepared by a procedure of typical coprecipitation methods [2,3]. Firstly, $50 \mathrm{~mL}$ mixture solution containing $0.6 \mathrm{Mol}$ $\mathrm{Mg}\left(\mathrm{NO}_{3}\right)_{2} \cdot 6 \mathrm{H}_{2} \mathrm{O}$ and $0.3 \mathrm{Mol} \mathrm{Al}\left(\mathrm{NO}_{3}\right)_{3} \cdot 9 \mathrm{H}_{2} \mathrm{O}(\mathrm{Mg} / \mathrm{Al}$ molar ratio $=2: 1$ ) was slowly added to a solution of $4.25 \mathrm{~g}$ $\mathrm{NaNO}_{3}(0.05 \mathrm{Mol})$ in $100 \mathrm{~mL}$ of water at room temperature with vigorously stirring under $\mathrm{N}_{2}$ atmosphere to prevent the formation of carbonate intercalated LDHs. The $\mathrm{pH}$ of the reaction mixture was adjusted $10.0 \pm 0.2$ by dropwise addition of $1 \mathrm{Mol} \mathrm{NaOH}$ solution. Then the resulting slurry was crystallized at $70^{\circ} \mathrm{C}$ for $48 \mathrm{~h}$. The white precipitate was isolated by filtration, washed with hot decarbonated water several times, and dried at $80^{\circ} \mathrm{C}$ for $24 \mathrm{~h}$.

2.4. Synthesis of $A C / S B E-\beta-C D$ Inclusion Complex Intercalated $L D H s$ by Swelling/Restoration Method. AC/SBE- $\beta$-CD inclusion complex intercalated LDHs were prepared by a procedure similar to the methods of Huang et al. [1]. $0.5 \mathrm{~g} \mathrm{MgAl}-$ $\mathrm{NO}_{3}$-LDHs was added to $200 \mathrm{~mL}$ of formamide, and then the mixture was allowed to stand for $24 \mathrm{~h}$ without stirring or shaking, and then a translucent colloidal suspension was obtained. Weighted $2.3 \mathrm{~g}$ AC/SBE- $\beta$-CD inclusion complex was put into the prepared colloidal suspension of the LDHs in formamide and stirred slowly for $24 \mathrm{~h}$. After having been centrifuged at $18000 \mathrm{rpm}$, the precipitate was washed with hot decarbonated water several times and dried at $80^{\circ} \mathrm{C}$ for $24 \mathrm{~h}$. The schematic representation for the formation of AC/SBE$\beta$-CD-LDHs by swelling/restoration method is shown in Scheme 2.

2.5. Characterization. X-ray diffraction (XRD) patterns of the samples were collected using a Bruker D8 Advance $\mathrm{XRD}$ diffractometer at $\mathrm{Cu} \mathrm{K} \alpha$ radiation and a fixed power source $(40 \mathrm{kV}$ and $40 \mathrm{~mA},=1.5406 \AA)$. Fourier-transform infrared spectroscopy (FT-IR) were recorded in the range $400-4000 \mathrm{~cm}^{-1}$ on a Nicolet NEXUS 470 Fourier-transform infrared spectrophotometer using $\mathrm{KBr}$ pellet technique. Thermogravimetry and differential thermal analysis (TGDTA) curves were obtained on a NETZSCH STA 449C instrument in the temperature range of $30-680^{\circ} \mathrm{C}$ with a heating rate of $10^{\circ} \mathrm{C} \mathrm{min}^{-1}$ in air atmosphere. A field emission scanning electron microscope (FSEM) (HITACHI S4800) and transmission electron microscope (TEM) (FEI Tecnai G20) were used to study the surface morphology of sample.

2.6. Release Performances of AC from AC/SBE- $\beta-C D-L D H s$. The release performances of AC from AC/SBE- $\beta$-CD-LDHs composite were determined essentially following our previous method [22]. 0.1 g of AC/SBE- $\beta$-CD-LDHs powder was added to $300 \mathrm{~mL}$ of phosphate citrate buffer solutions ( $\mathrm{pH} 4.8$ and $\mathrm{pH} 7.5$, resp.) and was stirred at $37^{\circ} \mathrm{C}$. At specified time intervals, $2 \mathrm{~mL}$ of solution was removed and filtered through $0.45 \mu \mathrm{m}$ microfiltration membrane. The accumulated amount of AC released into buffer solutions was measured momentarily using a UV-Vis spectrophotometer at $\lambda_{\max }=273 \mathrm{~nm}$ of AC. Runs were performed in triplicate. The release profiles were plotted as the relative release percentages of $\mathrm{AC}$ against time.

\section{Results and Discussion}

3.1. X-Ray Diffraction. Figure 1 shows the XRD patterns for AC/SBE- $\beta$-CD inclusion complex with ethanol washing (a), without ethanol washing (b), SBE- $\beta$-CD (c), and AC (d), respectively. As we can see, SBE- $\beta$-CD is amorphous, but $\mathrm{AC}$ is in crystalline form. The XRD patterns of AC/SBE- $\beta$-CD inclusion complex without ethanol washing show aceclofenac crystalline signals, which could be derived from adsorbed $\mathrm{AC}$ on the surface of $\mathrm{AC} / \mathrm{SBE}-\beta-\mathrm{CD}$ inclusion complex. In contrast, after washing with ethanol, the XRD pattern of Figure 1(a) shows only the amorphous bread peak of SBE- $\beta$ $\mathrm{CD}$, suggesting the formation of inclusion with $\mathrm{AC}$. So at the last step of the synthesis of AC/SBE- $\beta$-CD inclusion complex, ethanol was used to remove $\mathrm{AC}$ adsorbed on the complex.

Figure 2 shows the XRD pattern of $\mathrm{MgAl}-\mathrm{NO}_{3}$-LDHs (a) and AC/SBE- $\beta$-CD-LDHs composite prepared by swelling/ restoration method (b). As compared to the $\mathrm{MgAl}-\mathrm{NO}_{3}$ LDHs (Figure 2(a), $2 \theta=10.20^{\circ}, d_{003}=0.87 \mathrm{~nm}$ ), the basal reflection (003) of AC/SBE- $\beta$-CD-LDHs (Figure 2(a), $2 \theta=3.96^{\circ}, d_{003}=2.23 \mathrm{~nm}$ ) shifts to a lower $2 \theta$ angle. Therefore, the XRD result indicates that restoration of $\mathrm{AC} /$ SBE- $\beta$-CD-LDHs is formed when AC/SBE- $\beta$-CD inclusion 


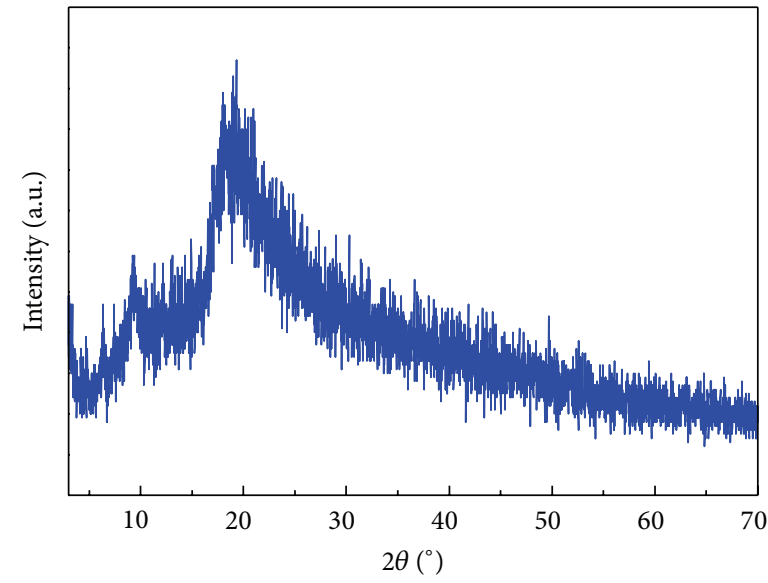

(a)

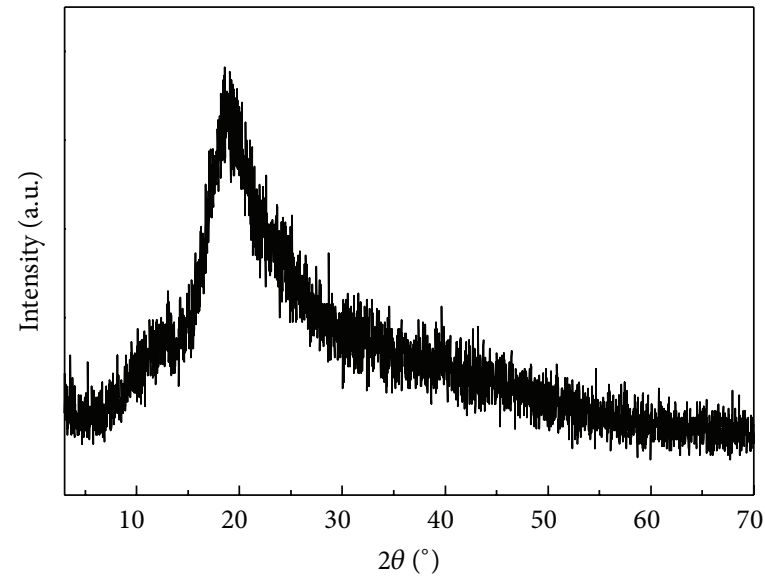

(c)

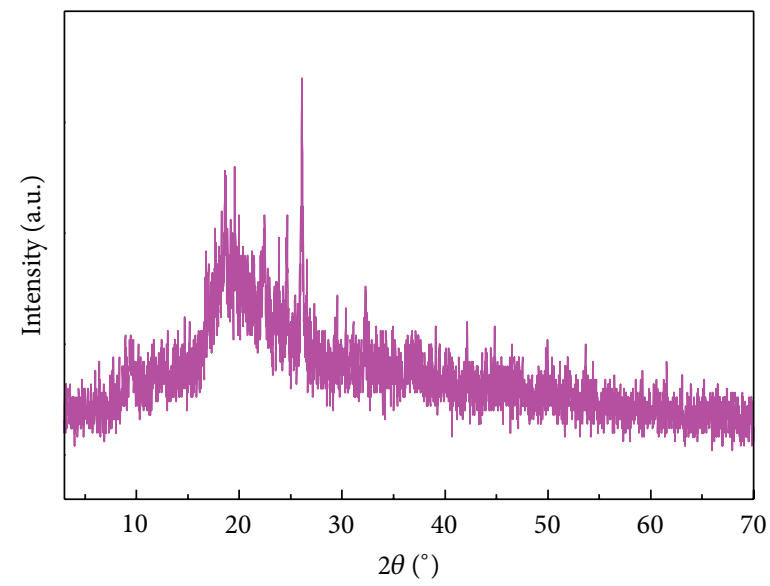

(b)

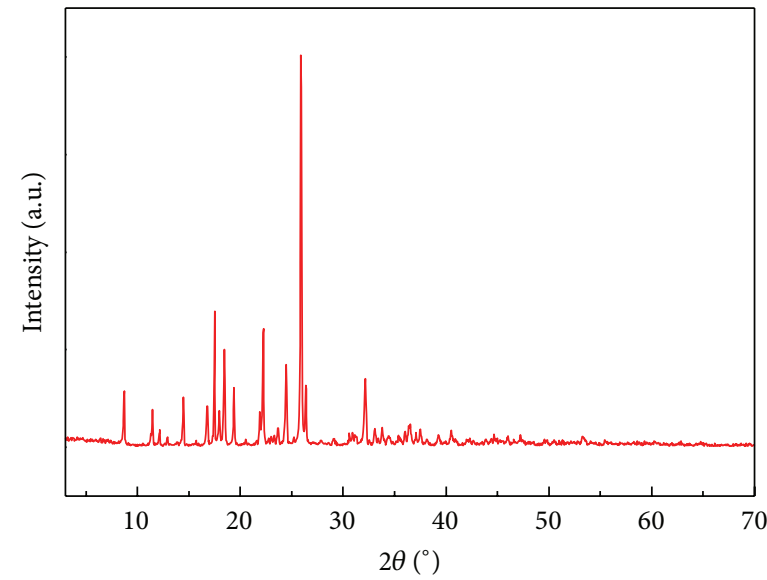

(d)

FIGURE 1: XRD patterns for AC/SBE- $\beta$-CD inclusion complex (a) with ethanol washing, (b) without ethanol washing, SBE- $\beta$-CD (c), and AC (d).

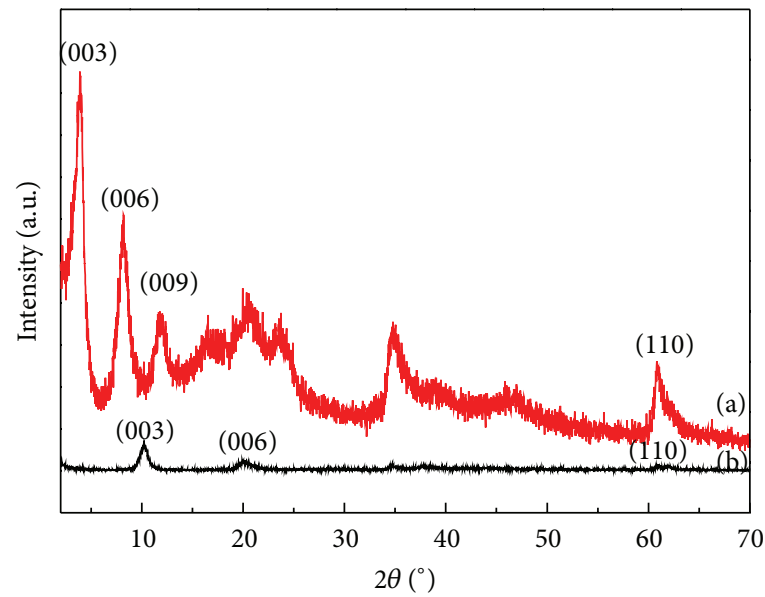

Figure 2: XRD patterns of MgAl-NO $\mathrm{NO}_{3}$-LDHs (a) and AC/SBE- $\beta$-CD-LDHs (b). 
<smiles>O=C(O)COC(=O)Cc1ccccc1Nc1c(Cl)cccc1Cl</smiles>

(a) Aceclofenac (AC)

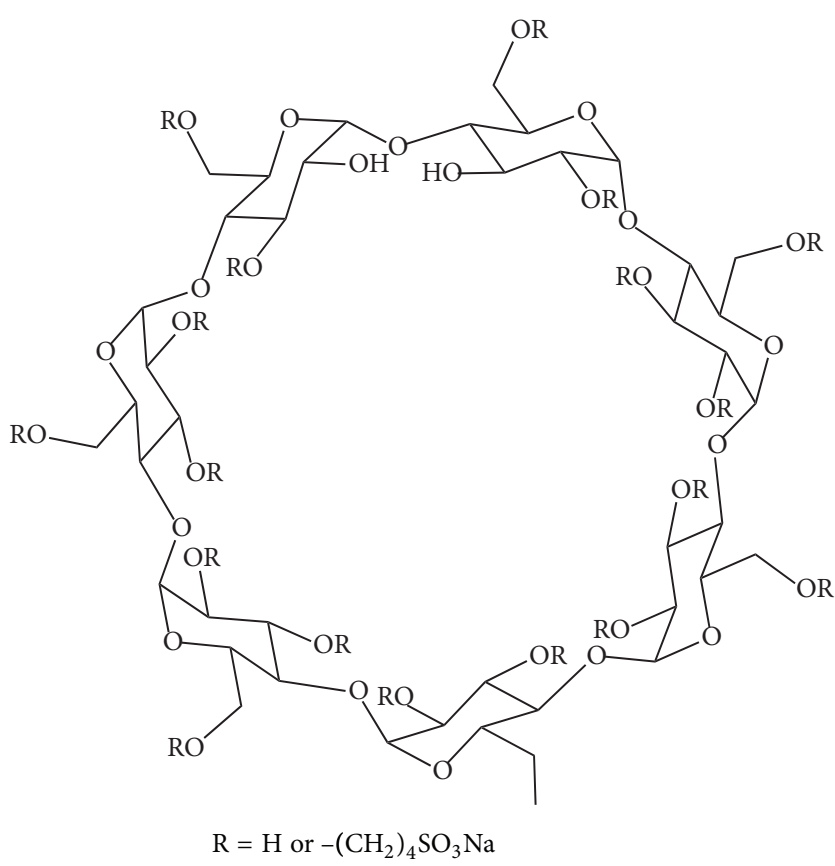

(b) Sulfobutyl ether- $\beta$-cyclodextrin (SBE- $\beta$-CD)

ScHeme 1: Structures of aceclofenac (a) and sulfobutyl ether- $\beta$-cyclodextrin (b).
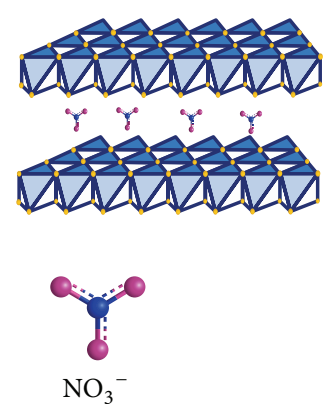
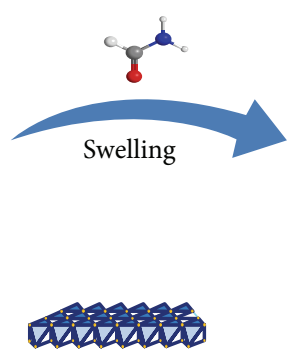

LDHs sheet
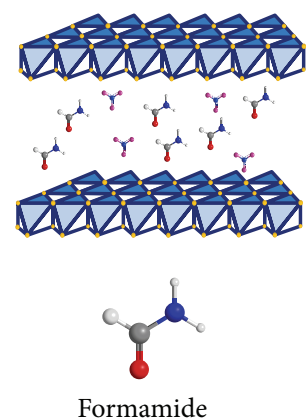
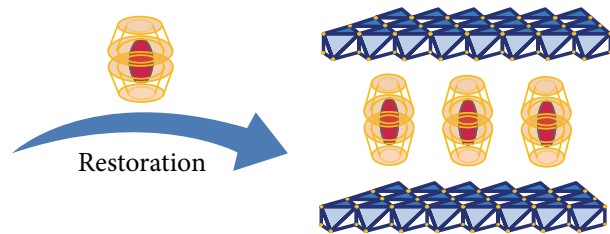

SBE- $\beta-C D$

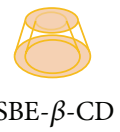

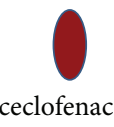

Scheme 2: Schematic formation of the AC/SBE- $\beta$-CD intercalated LDHs composite.

complex is placed in contact with colloidal suspension of the $\mathrm{MgAl}-\mathrm{NO}_{3}$-LDHs in formamide. Based on the basal spacing $d_{003}$ of $2.23 \mathrm{~nm}$ for AC/SBE- $\beta$-CD-LDHs observed by XRD and subtracting the thickness of brucite layer $(0.48 \mathrm{~nm})$, the gallery height is calculated to be $1.75 \mathrm{~nm}$, which is about double the size of that torus thickness of SBE- $\beta-\mathrm{CD}(0.78 \mathrm{~nm})$ [25]. Therefore, as shown in Scheme 1, it is suspected that $\mathrm{AC} / \mathrm{SBE}-\beta$-CD inclusion complex located in the form of monolayer arrangement.

3.2. Fourier-Transform Infrared Spectroscopy. Figure 3 shows the FT-IR spectra of MgAl-NO $-\mathrm{LDHs}(\mathrm{a}), \mathrm{AC}(\mathrm{b}), \mathrm{SBE}-$ $\beta$-CD (c), and AC/SBE- $\beta$-CD-LDHs composite (d), respectively. The FT-IR spectra of AC (Figure 3(b)) consisted of the sharp absorption bonds of $-\mathrm{NH}$ group $\left(3319 \mathrm{~cm}^{-1}\right)$ and of a carbonyl stretching band at $1716 \mathrm{~cm}^{-1}$ and $1717 \mathrm{~cm}^{-1}$ for $-\mathrm{C}=\mathrm{O}$ stretching of $\mathrm{COO}$ and $-\mathrm{COOH}$ group, respectively.
The peaks at $1589,1257,1149$, and $750 \mathrm{~cm}^{-1}$ are assigned to other major peaks for AC. In the spectrum of SBE- $\beta$ $\mathrm{CD}$ (Figure 3(c)), the absorption bands at $3442 \mathrm{~cm}^{-1}$ and $2940 \mathrm{~cm}^{-1}$ are due to the stretching vibration of $\mathrm{O}-\mathrm{H}$ and $-\mathrm{CH}_{2}$, respectively. The strong absorption bands at 1206 and $1044 \mathrm{~cm}^{-1}$ are the characteristic of stretching vibration of $\mathrm{C}-\mathrm{H}$ and $\mathrm{C}-\mathrm{O}-\mathrm{C}$ of glucose units [22]. As shown in Figure $3(\mathrm{~d})$, the spectra of $\mathrm{AC}$ and SBE- $\beta$-CD-LDHs are partially overlapped, and AC/SBE- $\beta$-CD-LDHs composite exhibited the main characteristic peaks of $A C, S B E-\beta-C D$, and metal-O stretching vibrations. These results indicate that $\mathrm{AC} / \mathrm{SBE}-\beta-\mathrm{CD}$ have been intercalated into composite by swelling/restoration method.

3.3. Surface Morphology. Figure 4 shows the scanning electron microscope morphology and transmission electron microscope image of AC/SBE- $\beta$-CD-LDHs. As we can see 


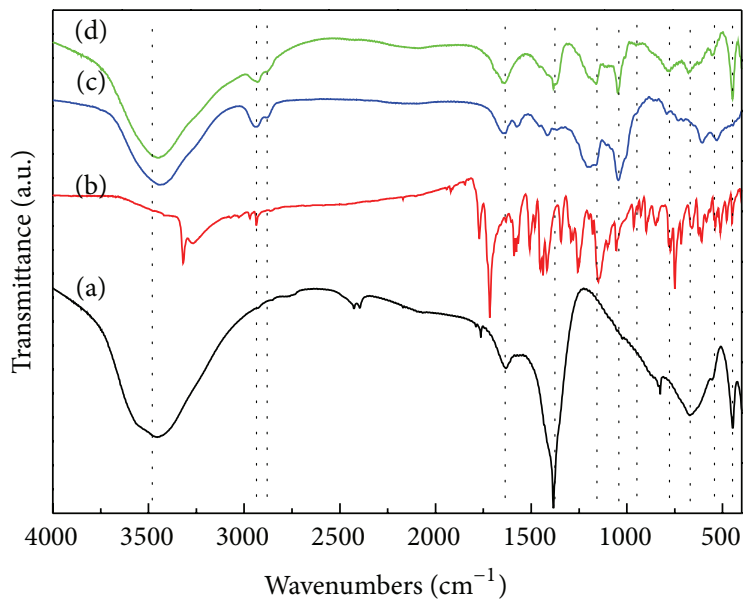

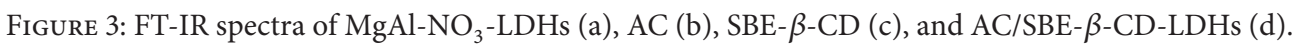

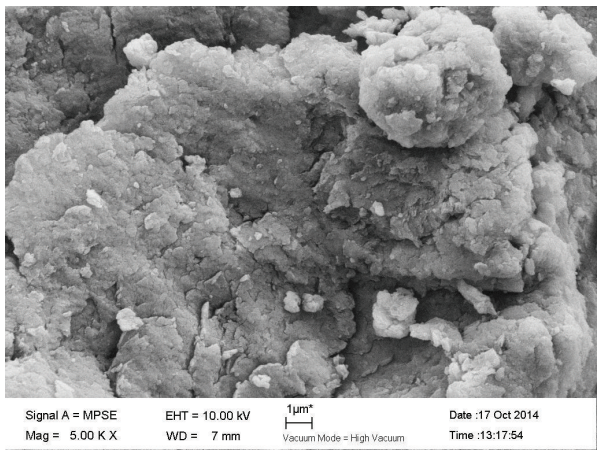

(a)

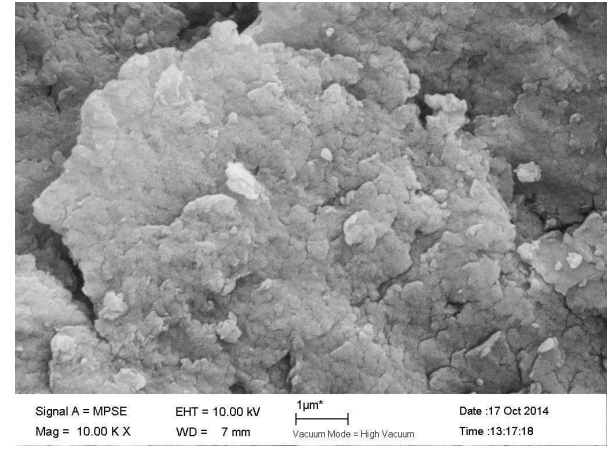

(b)

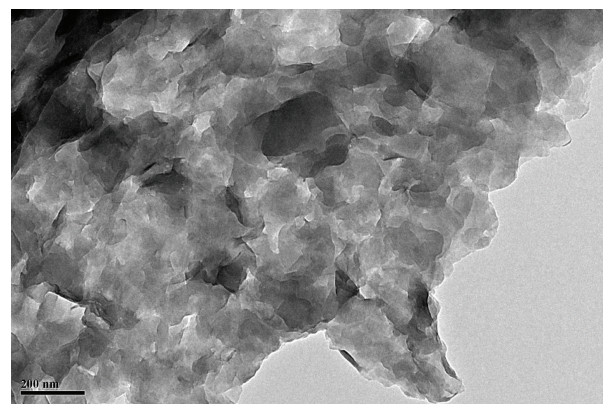

(c)

FIGURE 4: Scanning electron micrographs at low (a) and high (b) magnifications and transmission electron microscope image (c) for AC/SBE$\beta$-CD-LDHs.

the AC/SBE- $\beta$-CD-LDHs particles are of plate-like shape with slight agglomerates, which is typical morphology of intercalated LDHs.

3.4. Thermal Stability. The TG and DTA curves for the AC/SBE- $\beta$-CD-LDHs are shown in Figure 5. The thermal decomposition of AC/SBE- $\beta$-CD-LDHs was characterized by four weight loss steps (Figure 5): the first $\left(50-130^{\circ} \mathrm{C}\right.$ ) is due to loss of both adsorbed water and interlayer water molecules; the second $\left(130-260^{\circ} \mathrm{C}\right)$ is due to both the decomposition of the SBE- $\beta-C D$ and the elimination of interlayer water, which has a weak exothermic peak in the DTA curve; the third $\left(260-570^{\circ} \mathrm{C}\right)$ is a consequence of dehydroxylation and decomposition of SBE- $\beta-\mathrm{CD}$. The last stage $\left(590-630^{\circ} \mathrm{C}\right) \mathrm{can}$ be attributed to the combustion of SBE- $\beta-\mathrm{CD}$, which has a strong exothermic peak at $625^{\circ} \mathrm{C}$ in the DTA curve.

3.5. Controlled-Release Properties. The release of AC from AC/SBE- $\beta$-CD-LDHs composite was monitored via UV-Vis spectrophotometer. Figure 6 shows AC release performance of the composite in buffer solution at $\mathrm{pH} 4.8$ and $\mathrm{pH} 7.5$, respectively. As we can see, the $\mathrm{AC}$ release was rapid at the 


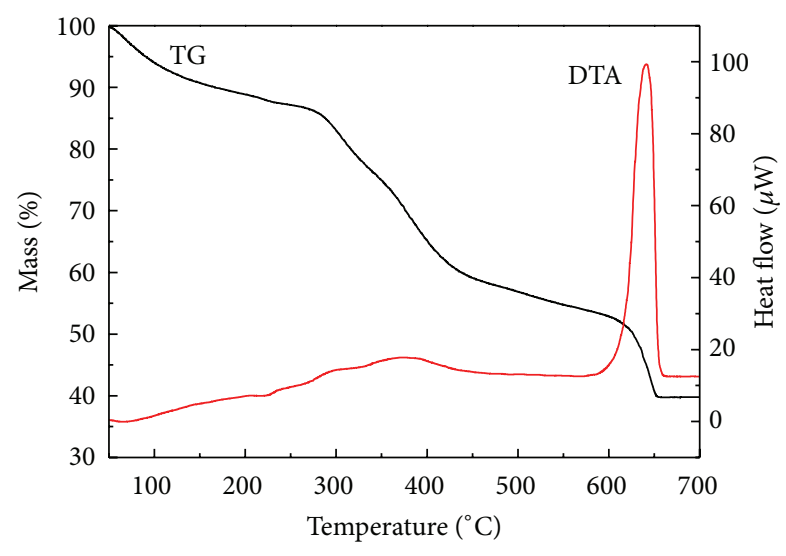

FIgURE 5: TG-DTA profiles of AC/SBE- $\beta$-CD-LDHs.

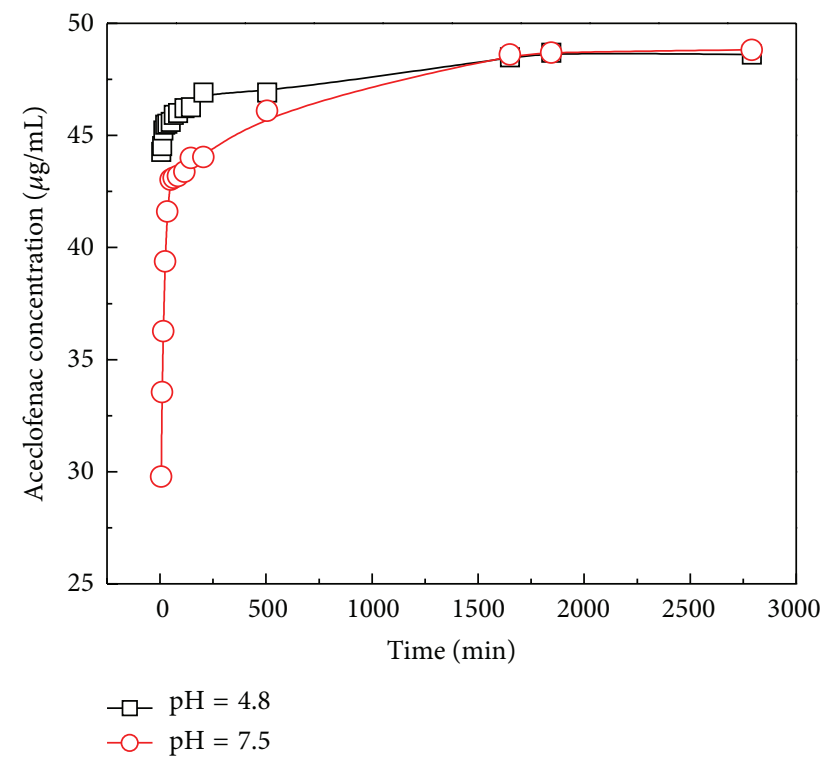

FIgURE 6: Release curves of AC/SBE- $\beta$-CD-LDHs composite in buffer solution at $\mathrm{pH} 7.5$ and $\mathrm{pH} 4.8$.

first 100 minutes and then slowed until it reached equilibrium at $\mathrm{pH}$ 4.8. However, a rapid release of AC occurred at the first $40 \mathrm{~min}$, which was followed by a slower release of AC until about $2000 \mathrm{~min}$. It was also found that the AC accumulative concentration at $\mathrm{pH}$ of $7.5(48.8 \mu \mathrm{g} / \mathrm{mL})$ was nearly the same as that at $\mathrm{pH}$ of $4.8(48.6 \mu \mathrm{g} / \mathrm{mL})$. Considering the poor solubility of AC [22], thus we can conclude that the present SBE- $\beta$-CD intercalated LDHs not only enhanced the dissolution profile of AC but also exhibited a controlledrelease process.

\section{Conclusion}

$\mathrm{AC} / \mathrm{SBE}-\beta$-CD-LDHs nanocomposite with larger AC/SBE$\beta$-CD inclusion complex in the LDHs interlayer can be easily prepared by swelling/restoration method. As compared to $\mathrm{MgAl}-\mathrm{NO}_{3}$-LDHs, the basal reflection (003) of AC/SBE$\beta$-CD-LDHs shifts to a lower $2 \theta$ angle $\left(3.96^{\circ}\right)$, and the
AC/SBE- $\beta$-CD inclusion complex in the LDHs interlayer has monolayer arrangement. The AC/SBE- $\beta$-CD-LDHs prepared by swelling/restoration reaction exhibits a controlled-release property with higher concentration of AC.

\section{Conflict of Interests}

The authors declare that there is no conflict of interests regarding the publication of this paper.

\section{Acknowledgments}

This research was funded by the National Natural Science Foundation of China (no. 21106085) and supported by Program for Liaoning Excellent Talents in University (no. LJQ2014042).

\section{References}

[1] G. Huang, S. Ma, X. Zhao, X. Yang, and K. Ooi, "Intercalation of bulk guest into $\mathrm{LDH}$ via osmotic swelling restoration reaction control of the arrangements of thiacalix [4] arene anion intercalates," Chemistry of Materials, vol. 22, no. 5, pp. 1870-1877, 2010.

[2] X. Duan and D. G. Evans, Layered Double Hydroxides, Springer, Berlin, Germany, 2006.

[3] V. Reves, Layered Double Hydroxides: Present and Future, Nova Science Publishers, New York, NY, USA, 2001.

[4] F. Cavani, F. Trifirò, and A. Vaccari, "Hydrotalcite-type anionic clays: preparation, properties and applications," Catalysis Today, vol. 11, no. 2, pp. 173-301, 1991.

[5] K. H. Goh, T. T. Lim, and Z. Dong, "Application of layered double hydroxides for removal of oxyanions: a review," Water Research, vol. 42, no. 6-7, pp. 1343-1368, 2008.

[6] R. Marangoni, M. Bouhent, C. Taviot-Guého, F. Wypych, and F. Leroux, " $\mathrm{Zn}_{2} \mathrm{Al}$ layered double hydroxides intercalated and adsorbed with anionic blue dyes: a physico-chemical characterization," Journal of Colloid and Interface Science, vol. 333, no. 1, pp. 120-127, 2009.

[7] V. Rives, M. Arco, and C. Martín, "Layered double hydroxides as drug carriers and for controlled release of non-steroidal antiinflammatory drugs (NSAIDs): a review," Journal of Controlled Release, vol. 169, no. 1-2, pp. 28-39, 2013.

[8] T.-H. Kim, G. J. Lee, J.-H. Kang, H.-J. Kim, T.-I. Kim, and J.-M. Oh, "Anticancer drug-incorporated layered double hydroxide nanohybrids and their enhanced anticancer therapeutic efficacy in combination cancer treatment," BioMed Research International, vol. 2014, Article ID 193401, 11 pages, 2014.

[9] A. C. T. Cursino, F. da Silva Lisboa, A. dos Santos Pyrrho, V. P. de Sousa, and F. Wypych, "Layered double hydroxides intercalated with anionic surfactants/benzophenone as potential materials for sunscreens," Journal of Colloid and Interface Science, vol. 397, pp. 88-95, 2013.

[10] S. Li, Y. Shen, M. Xiao, D. Liu, L. Fa, and K. Wu, "Intercalation of 2,4-dihydroxybenzophenone-5-sulfonate anion into $\mathrm{Zn} / \mathrm{Al}$ layered double hydroxides for UV absorption properties," Journal of Industrial and Engineering Chemistry, vol. 20, no. 4, pp. 1280 1284, 2014.

[11] S. Ma, L. Du, J. Wang et al., "Structural adjustment during intercalation of macrocyclic crown ether into $\mathrm{LDH}$ via 
swelling/restoration reaction: staging formation and mechanism insights," Dalton Transactions, vol. 40, no. 38, pp. 98359843, 2011.

[12] H. Zhao and G. F. Vance, "Intercalation of carboxymethyl$\beta$-cyclodextrin into magnesium-aluminum layered double hydroxide," Dalton Transactions, vol. 11, pp. 1961-1965, 2000.

[13] J. Wang, M. Wei, G. Rao, D. G. Evans, and X. Duan, "Structure and thermal decomposition of sulfated $\beta$-cyclodextrin intercalated in a layered double hydroxide," Journal of Solid State Chemistry, vol. 177, no. 1, pp. 366-371, 2004.

[14] S. Sasaki, Y. Yokohama, S. Aisawa, H. Hirahara, and E. Narita, "Intercalation of natural cyclodextrins into layered double hydroxide by calcination-rehydration reaction," Chemistry Letters, vol. 34, no. 8, pp. 1192-1193, 2005.

[15] H. Nakayama, K. Kuwano, and M. Tsuhako, "Controlled release of drug from cyclodextrin-intercalated layered double hydroxide," Journal of Physics and Chemistry of Solids, vol. 69, no. 5-6, pp. 1552-1555, 2008.

[16] X. Xue, Q. Gu, G. Pan et al., "Nanocage structure derived from sulfonated $\beta$-cyclodextrin intercalated layered double hydroxides and selective adsorption for phenol compounds," Inorganic Chemistry, vol. 53, no. 3, pp. 1521-1529, 2014.

[17] S. Sasaki, S. Aisawa, H. Hirahara, A. Sasaki, H. Nakayama, and E. Narita, "Synthesis and adsorption properties of $p$-sulfonated calix[4 and 6]arene-intercalated layered double hydroxides," Journal of Solid State Chemistry, vol. 179, no. 4, pp. 1129-1135, 2006.

[18] S. Sasaki, S. Aisawa, H. Hirahara, A. Sasaki, H. Nakayama, and E. Narita, "Synthesis of p-sulfonated calix[4] arene-intercalated layered double hydroxides and their adsorption properties for organic molecules," Journal of the European Ceramic Society, vol. 26, no. 4-5, pp. 655-659, 2006.

[19] G. Huang, S. Ma, X. Zhao, X. Yang, and K. Ooi, “Topotactic intercalation of a bulky organic anion (thiacalix[4]arene) into LDH through an osmotic swelling/restoration reaction in formamide," Chemical Communications, no. 3, pp. 331-333, 2009.

[20] S. Ma, J. Wang, L. Du et al., "A new method for fast intercalation of bulk crown ether guest into LDH," Journal of Colloid and Interface Science, vol. 393, no. 1, pp. 29-35, 2013.

[21] M. Dooley, C. M. Spencer, and C. J. Dunn, "Aceclofenac: a reappraisal of its use in the management of pain and rheumatic disease," Drugs, vol. 61, no. 9, pp. 1351-1378, 2001.

[22] S. Li, Y. Shen, D. Liu, L. Fan, K. Wu, and M. Xiao, "Synthesis of aceclofenac/hydroxypropyl- $\beta$-cyclodextrin intercalated layered double hydroxides and controlled release properties," Functional Materials Letters, vol. 6, no. 3, Article ID 1350030, 4 pages, 2013.

[23] M. Nasr, S. Mansour, N. D. Mortada, and A. A. Elshamy, "Vesicular aceclofenac systems: a comparative study between liposomes and niosomes," Journal of Microencapsulation, vol. 25, no. 7, pp. 499-512, 2008.

[24] K. Dua, K. Pabreja, and M. V. Ramana, "Enhancement of dissolution behavior of aceclofenac by complexation with $\beta$-cyclodextrin-choline dichloride coprecipitate," Journal of Dispersion Science and Technology, vol. 32, no. 10, pp. 1477-1484, 2011.

[25] H. Dodziuk, Cyclodextrins and Their Complexes, WILEY-VCH, Weinheim, Germany, 2006. 

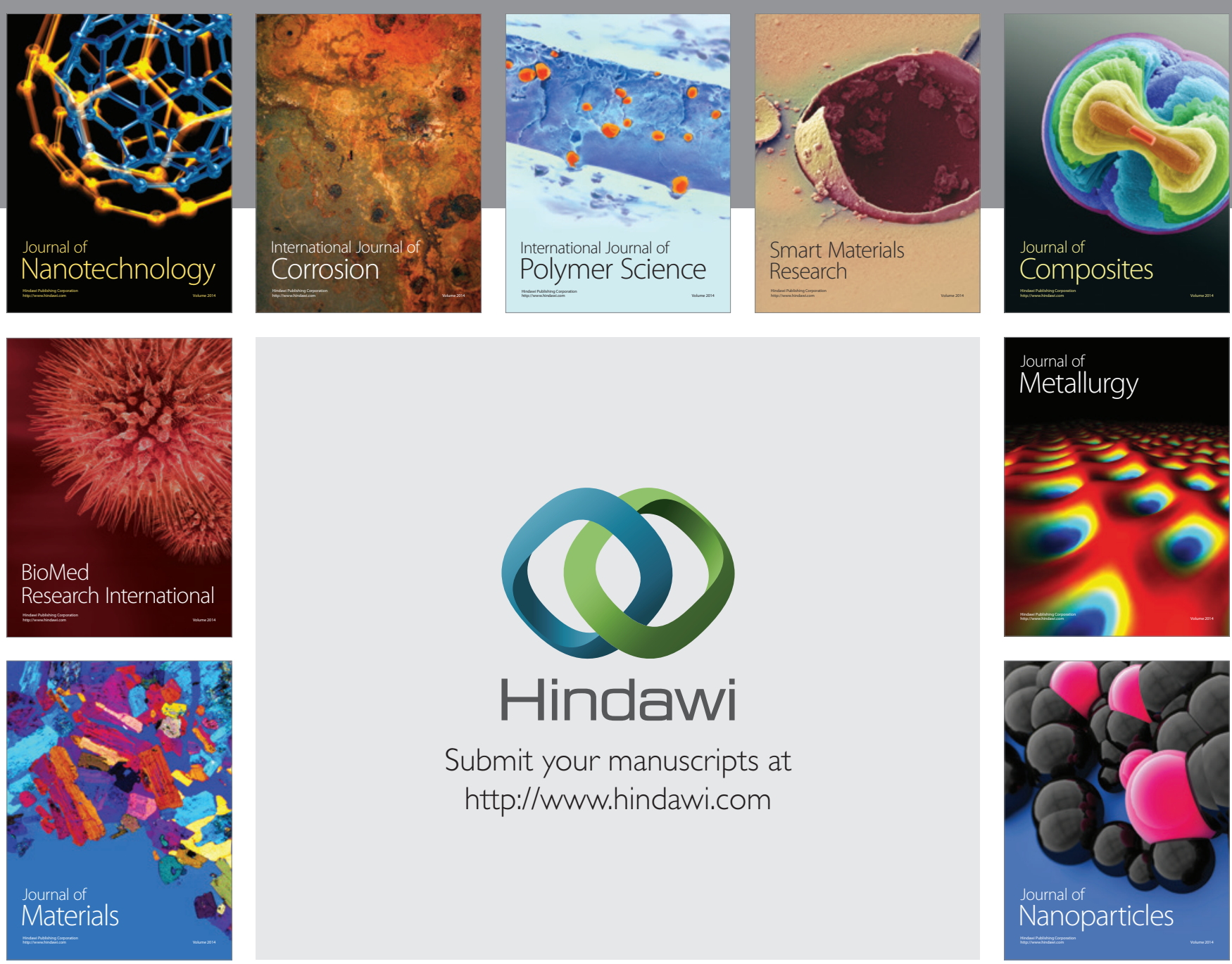

Submit your manuscripts at http://www.hindawi.com
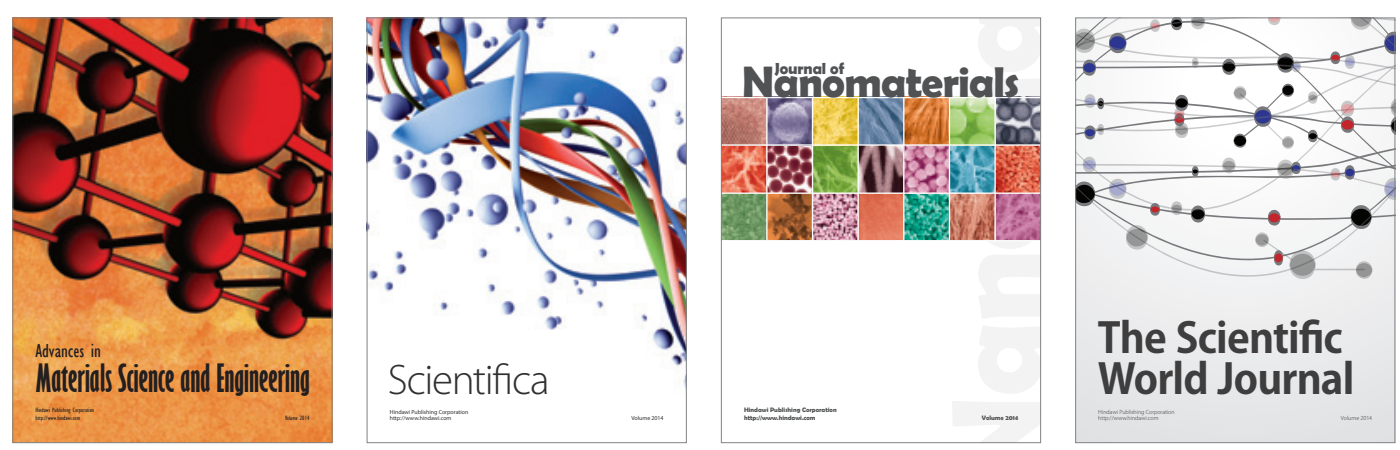

\section{The Scientific World Journal}
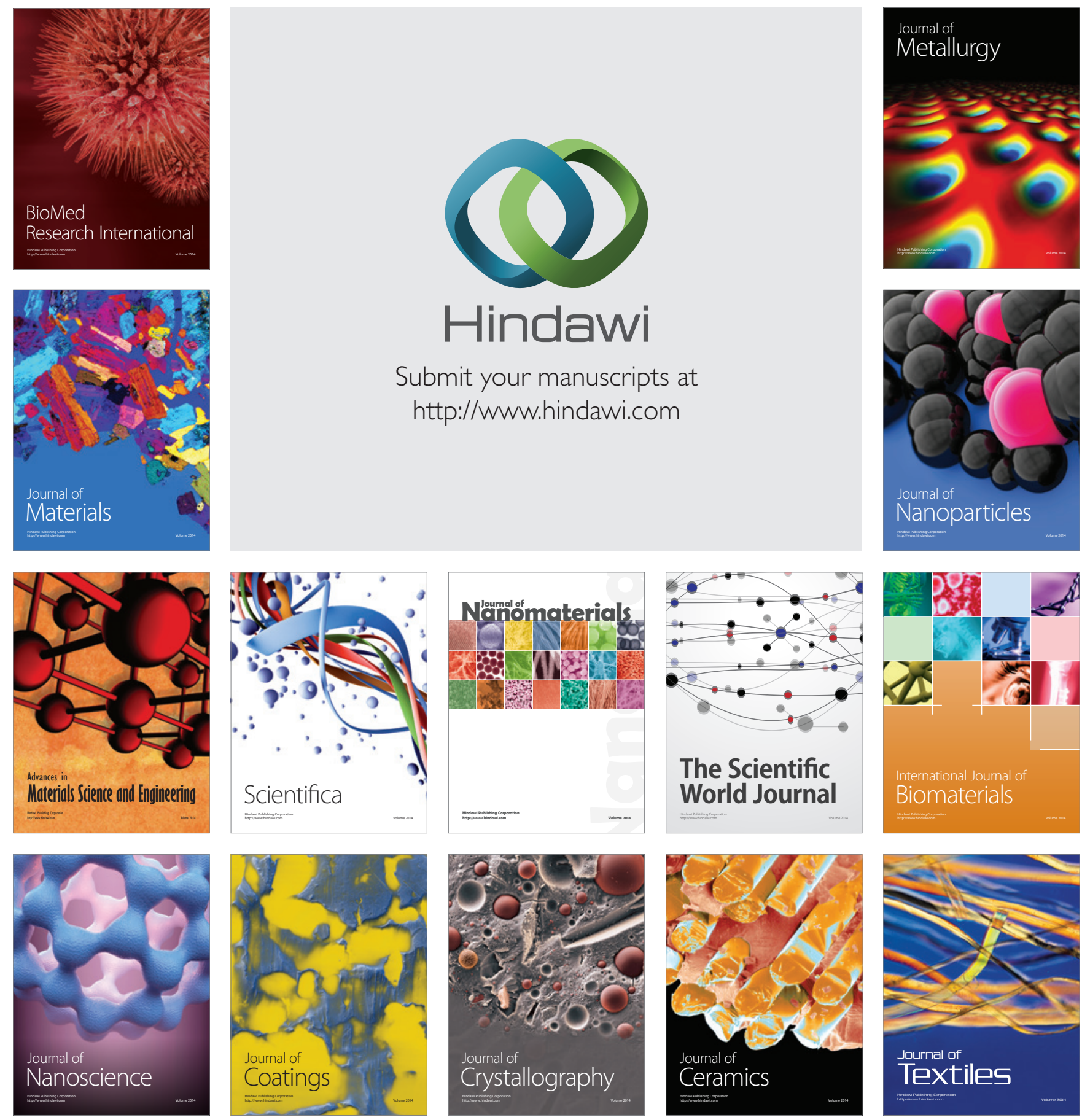